\title{
Fabrication and optimization of ethylene-producing tablet
}

\author{
Do Su Park, Cheon Soon Jeong* \\ Department of Horticulture, Kangwon National University, Chuncheon 24341, Korea
}

에틸렌 발생 tablet 제조 및 활성 최적 조건 구명

\author{
박도수·정천순* \\ 강원대학교 원예학과
}

\begin{abstract}
Ethylene $\left(\mathrm{C}_{2} \mathrm{H}_{4}\right)$ is a naturally occurring hormone in some fruit. This study was carried out to manufacture ethylene-producing tablets. The Ethylene-producing tablets were manufactured from ethephon and excipient mixtures, including Prosolv, Hydroxypropylmethylcellulose (HPMC) and Crosscamellose. Ethylene production increased with the increases in temperature. In the aspect of $\mathrm{pH}$ condition, ethylene productions at $\mathrm{pH} 7.0$ and $\mathrm{pH} 9.0$ were less than $2 \mathrm{ppm}$. On the other hand, at $\mathrm{pH}$ 13.0, ethylene production from the Prosolv, HPMC, and Crosscamellose tablets was 94.05, 126.28, and $100.11 \mathrm{ppm}$, respectively. The friability of the Prosolv and HPMC tablets were 0.1 and $0.3 \%$, respectively, while the Crosscamellose tablet was $54.1 \%$. indicating that the Crosscarmellose tablet was not appropriate as an ethylene production tablet. In addition, there were huge variations in disintegration times; the Prosolv, Crosscamelose, and HPMC tablets took 1, $5 \mathrm{~min}$, and $7 \mathrm{~min}$ more than respectively. Ethylene production was gradually increased up to $20 \mathrm{hr}$ for the Prosolv tablet and then remained stable.
\end{abstract}

Key words : activator, ethephon, ethylene, tablet

\section{서 론}

에틸렌 $\left(\mathrm{C}_{2} \mathrm{H}_{4}\right)$ 은 과실의 성숙촉진이나 후숙 및 노화에 관 여하는 식물호르몬이다. 에틸렌은 수확 후 원예산물의 노 화를 촉진시키기 때문에 이에 따른 경제적인 손실을 방지하 기 위해 에틸렌 발생억제를 위해 많은 연구가 진행되고 있지만, 역으로 그 성질을 응용하여 이용하기도 한다. 수확 후 키위를 후숙하거나(1) 바나나, 감귤 등 일부 원예산물은 에틸렌 처리를 통하여 상품가치를 높일 수 있고, Park 등(2) 은 에틸렌을 이용한 떫은감의 탈삽을 보고하였다. 또한, 수확 후 포도의 낱알 가공품 제조 시 에틸렌 처리가 효과적 이라는 연구가 보고되었다(3). 한편, 에테폰(Ethephon)은 에 틸렌을 발생하는 생장조절물질로서 $\mathrm{pH} 2.0$ 이하의 조건에

*Corresponding author. E-mail : jeongcs@kangwon.ac.kr Phone : 82-33-250-6409, Fax : 82-33-259-5561

Received 4 September 2015; Revised 7 December 2015; Accepted 13 January 2016.

Copyright (c) The Korean Society of Food Preservation. All rights reserved.
서는 안정하나 $\mathrm{pH} 5.0$ 이상으로 상승하면 분해되어 에틸렌 을 생성한다. 이러한 이유로 식물 체내에 흡수 시 에틸렌을 발생시키고, 에테폰을 식물에 처리 시 식물 내 에틸렌 생성 에 매우 효과적이라고 보고된 바 있다(4). 이러한 에테폰은 과실의 성숙 및 착색촉진제로 이용되고 있다(1,5). 하지만, 시판되고 있는 에테폰 액제는 과실에 처리할 때 분무, 침지 등을 함으로써 에테폰이 잔류되는 단점이 있다. 이에 본 연구에서는 간편하게 에틸렌을 처리할 수 있도록 에틸렌 발생 타블렛 개발과 에틸렌 가스 활성 최적 조건을 구명하 여 원예산물의 상품성 향상에 활용하고자 수행하였다.

\section{재료 및 방법}

\section{타블렛 제조 및 물성 측정}

에틸렌 발생 타블렛은 영일화학에서 제조한 2-chloroethyl phosphonic acid(Ethephon) 원제와 Prosolv smcc50 부형제, HPMC 부형제, Crosscamellose 부형제와 혼합하여(에테폰 $5 \%$, 부형제 95\%) 타정기(KLTP-50, Koreamedi, Korea)를 
이용하여 제조사의 프로토콜에 따른 타정조건으로 타정하 였다. 제조한 타블렛의 경도는 HDT-300 Hardness Tester (Logan, USA)를 이용하여 측정하였고, 정제에 일정한 충격 을 가할 때 생성되는 분말량을 나타내는 마손도 측정은 마손도 측정기 Friabilator(KUKJE ENG, Korea)를 사용하였 다. 정제가 시험액 안에서 분산되는 시간을 나타내는 붕해 도는 Disintegration tester(KUKJE ENG, Korea)를 이용하여 측정하였다.

\section{활성 조건}

상기에서 제조한 타블렛의 최적 활성 조건을 구명하기 위해 activator로서 $\mathrm{KOH}$ 를 이용하여 $\mathrm{pH} 7.0,9.0,11.0$ 및 13.0 으로 설정하여 24시간 동안 $4 \mathrm{~L}$ 용기에 가스를 포집한 후, 용기 내의 기체 $1 \mathrm{~mL}$ 를 gas-tight syringe로 채취하여 gas chromatography(GC-2010, SHIMADZU, Japan)에 주입 해서 에틸렌의 발생량을 계산하였다. GC의 분석조건은 주 입온도를 $200^{\circ} \mathrm{C}$ 로 하였고, detecter는 $\mathrm{FID}$ 로 온도 $250^{\circ} \mathrm{C}$, column은 shin wax 0.25(shimadzu, Japan)를 사용하였으며, oven 온도는 $45^{\circ} \mathrm{C}$ 로 설정하였다. 이동 gas는 질소를 사용하 였으며, 유속 $14.9 \mathrm{~mL} / \mathrm{min}$ 의 조건에서 측정하였다. 온도조 건별 에틸렌 발생량을 측정하기 위해 제조된 타블렛을 activator $\mathrm{pH} 13.0$ 조건에서 처리하여 $10,15,20$ 및 $25^{\circ} \mathrm{C}$ 의 항온기에 각각 넣고 에틸렌 발생량을 측정하여 가장 많은 양의 에틸렌을 발생시키는 온도 조건을 구명하였다. 최종 선정 부형제의 시간대별 에틸렌발생량을 측정하기 위해 activator $\mathrm{pH} 13.0,25^{\circ} \mathrm{C}$ 온도조건에서 4 시간 간격으로 4 , $8,12,16,20$ 및 24 시간 까지 측정하였다.

\section{통계처리}

모든 실험은 5 회 반복 측정하여 그 평균값을 나타냈으며, 각 조건별 측정 결과는 SPSS statics 21 program을 이용하여 평균과 표준편차를 구하고 일원배치분산분석(one way ANOVA)을 실시한 후, Duncan's multiple range test를 실시 하여 유의성을 검정하였다. 또한 Microsoft Excel 2007 프로 그램을 이용하여 표준오차를 구하였다.

\section{결과 및 고찰}

부형제 종류에 따라 개발한 타블렛의 온도조건별 에틸렌 발생량은 Fig. 2에 나타냈다. 모든 부형제에서 온도가 높을 수록 에틸렌 발생량이 많았고, HPMC 부형제에서 대체적으 로 타 부형제에 비해 많은 에틸렌 발생을 보였다. 각각의 타블렛은 에틸렌발생 농도가 $10^{\circ} \mathrm{C}$ 조건에서는 $12.23 \mathrm{ppm}$, $15^{\circ} \mathrm{C}$ 조건에서 $14.12 \mathrm{ppm}$ 수준으로 나타났다. $20^{\circ} \mathrm{C}$ 조건에 서는 Prosolv 72.21 ppm, HPMC 100.34 ppm, Crosscamellose $87.16 \mathrm{ppm}$ 으로 나타났다. $25^{\circ} \mathrm{C}$ 조건의 경우 Prosolv 부형제
는 $94.05 \mathrm{ppm}$, Crosscamellose $100.11 \mathrm{ppm}, \mathrm{HPMC} 126.28$ $\mathrm{ppm}$ 으로 나타났다. 온도가 높을수록 타블렛의 에틸렌 발생 량은 유의적인 증가를 보였는데 $(\mathrm{p}<0.05)$, 이는 온도가 높아 짐에 따라 에테폰에서 에틸렌으로의 기화가 촉진되는 결과 로 해석되고, Lougheed and Franklin(6)이 보고한 에테폰을 처리 시 온도가 높을수록 에틸렌 발생량이 높았다는 연구결 과와 유사하였다. 부형제에 따른 에틸렌 발생량 차이는 같 은 압력으로 타정하였을 때 각각의 부형제의 특성상 타블렛 의 에테폰 함유량이 달라서 나타난 결과로 판단된다.

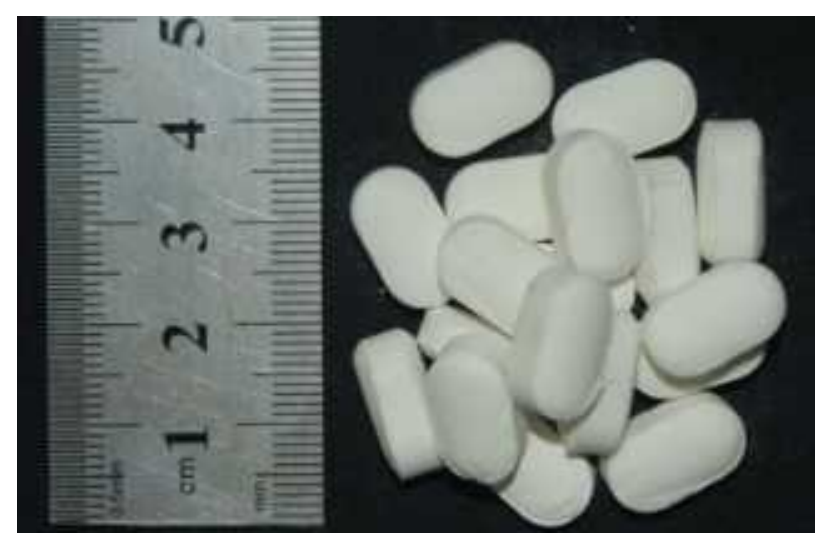

Fig. 1. Shape of ethylene-producing tablet.

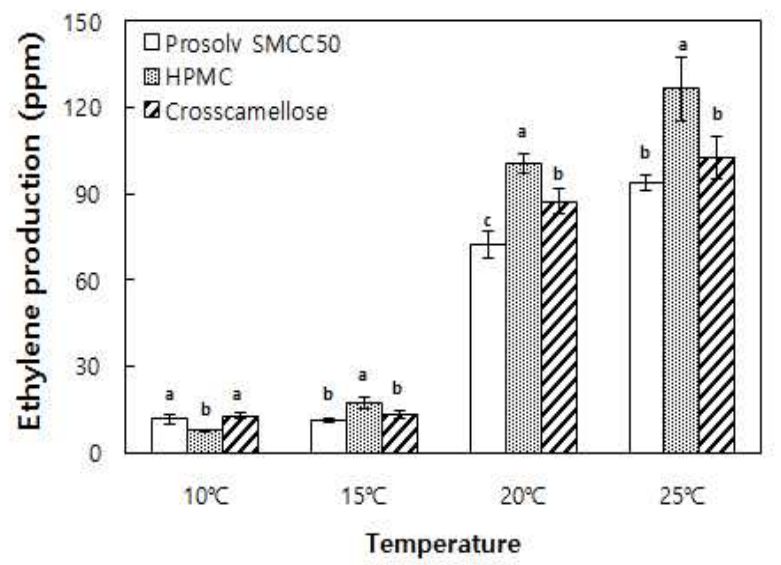

Fig. 2. Ethylene evolution from three tablets of ethephon and excipient mixtures, including Crosscamellose, HPMC, and Prosolv SMCC 50, depending on treatment temperatures in sealed jars.

Vertical bars represent the means $\pm S E$ ( $n=5$ ). Different letters above the bars indicate significant difference, according to the Duncan's multiple range test at $p=0.05$. The comparison was made within each temperature condition.

Activator의 $\mathrm{pH}$ 조건별 에틸렌 발생량은 Fig. 3에 나타냈 다. $\mathrm{pH} 7.0$ 및 9.0 조건에서는 모든 타블렛의 에틸렌 발생량 이 약 $2 \mathrm{ppm}$ 으로 미미하였다. 반면, $\mathrm{pH} 13.0$ 조건에서는 $100 \mathrm{ppm}$ 수준의 에틸렌이 발생하였다. Activator $\mathrm{pH}$ 가 높을 수록 타블렛의 에틸렌 발생량은 유의적으로 증가하였다 $(\mathrm{p}<0.05)$. 에테폰의 특성상 알칼리조건에서 에틸렌발생량 이 증가되어 이와 같은 결과가 나온 것으로 생각된다. 
Warner와 Leopold(7)은 에테폰이 에틸렌을 생성하기 위한 최소 $\mathrm{pH}$ 는 5.0 이며, $\mathrm{pH}$ 가 높아짐에 따라 에틸렌 발생량이 많아진다고 보고하였고, 본 연구에서도 이와 유사한 결과 를 보였다.

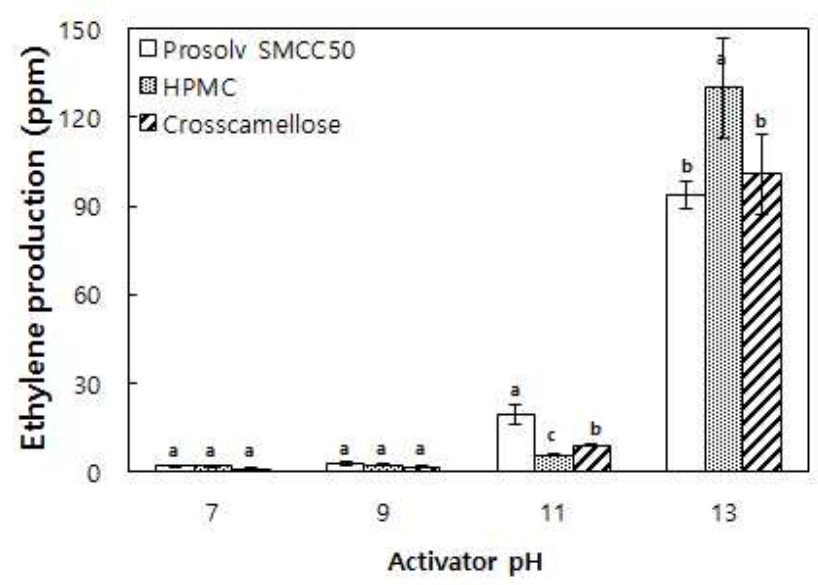

Fig. 3. Ethylene evolution from three tablets of ethephon and excipient mixtures, including Crosscamellose, HPMC, and Prosolv SMCC 50, depending on different activator $\mathrm{pH}$ at $25^{\circ} \mathrm{C}$ in sealed jars.

Vertical bars represent the means $\pm \mathrm{SE}(\mathrm{n}=5$ ). Different letters above the bars indicate significant difference, according to the Duncan's multiple range test at $\mathrm{p}=0.05$. The comparison was made within each $\mathrm{pH}$ condition.

부형제 종류에 따른 타블렛의 경도와 마손도는 Table 1 과 같다. 타블렛의 경도는 Prosolv 부형제 $4.16 \mathrm{kp}, \mathrm{HPMC}$ $14.27 \mathrm{kp}$, Crosscamellose $2.04 \mathrm{kp}$ 로 조사되었다. 각 부형제 에 따른 마손도는 Prosolv 부형제 $0.1 \%, \mathrm{HPMC}$ 부형제 $0.3 \%$, Crosscamelose 부형제 $54.1 \%$ 로 나타났다. 일반적으로 정제 의 마손율이 그 질량의 $1 \%$ 이하이어야 보관 및 운송에 적합하며, 마손율이 $50 \%$ 이상이었던 Crosscamellose 타블 렛은 보관 및 운송에는 어려울 것으로 판단된다.

Table 1. Physical properties of the ethylene-producing tablets $(n=20)$.

\begin{tabular}{cccc}
\hline Tablet & $\begin{array}{c}\text { Weight } \\
(\mathrm{mg})\end{array}$ & $\begin{array}{c}\text { Hardness } \\
(\mathrm{kp})\end{array}$ & $\begin{array}{c}\text { Friability } \\
(\%)\end{array}$ \\
\hline Prosolv SMCC50 & $360 \pm 10^{\mathrm{B} 1)}$ & $4.16 \pm 1.0^{\mathrm{B}}$ & $0.1 \pm 0.05^{\mathrm{B}}$ \\
HPMC & $420 \pm 10^{\mathrm{A}}$ & $14.27 \pm 1.0^{\mathrm{A}}$ & $0.3 \pm 0.10^{\mathrm{B}}$ \\
Crosscamellose & $380 \pm 10^{\mathrm{B}}$ & $2.04 \pm 1.0^{\mathrm{B}}$ & $54.1 \pm 5.00^{\mathrm{A}}$ \\
\hline
\end{tabular}

${ }^{1)}$ Means with standard error within the same column followed by a common letter are not significantly different at $\mathrm{p}<0.05$ with Duncan's multiple range test.

부형제에 따른 붕해도는 Prosolv 부형제에서 가장 빠르 게 붕해되었으며, 붕해시간은 1 분 미만으로 나타났다(Fig. 4). Crosscamellose 부형제는 약 5 분 정도에 완전히 붕해가 되었으며, HPMC 부형제의 경우 젤리막이 형성되면서 붕해 가 이루어지지 않았다( $\mathrm{p}<0.05)$. HPMC는 노란색을 띄는 섬
유상의 가루로 약물의 방출 속도를 조절하기 위해 첨가제로 사용되며, 물에 용해 시 젤리막을 형성하는 특징이 있다. 이와 같은 특징이 타블렛 처리 후 사후관리 문제에도 영향 을 주기 때문에 본 연구에서는 부적합 하다고 판단된다. 한편, 정제의 붕해도는 부형제에 종류에 따른 영향이 가장 큰 요인으로 보고된 바 있다(8,9)

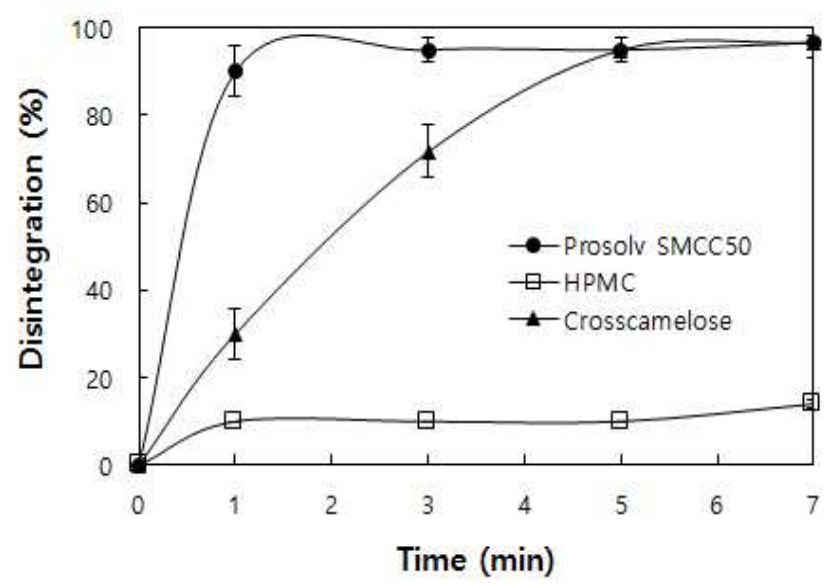

Fig. 4. Disintegration times for each tablet.

Vertical bars represent the means $\pm \mathrm{SE}(\mathrm{n}=5)$.

최종 선정된 Prosolv SMCC 50 부형제의 시간대별 에틸 렌 발생을 알아보기 위해 4시간 간격으로 가스포집 24시간 까지 에틸렌 발생량을 측정하였다(Fig. 5). 가스포집 4시간 째 에틸렌발생량은 $10.21 \mathrm{ppm}$ 으로 나타났다. 이후 점차 증가하여 포집 12시간 째 $63.27 \mathrm{ppm}, 20$ 시간 째 $104.12 \mathrm{ppm}$ 으로 조사되었다. 24시간 째 에틸렌 농도는 $107.28 \mathrm{ppm}$ 으로 가스포집 20시간 이후의 발생량은 미미하였다. 따라서 제 조된 타블렛은 처리 20시간까지 지속적으로 에틸렌가스를 발생하는 것으로 판명되었다.

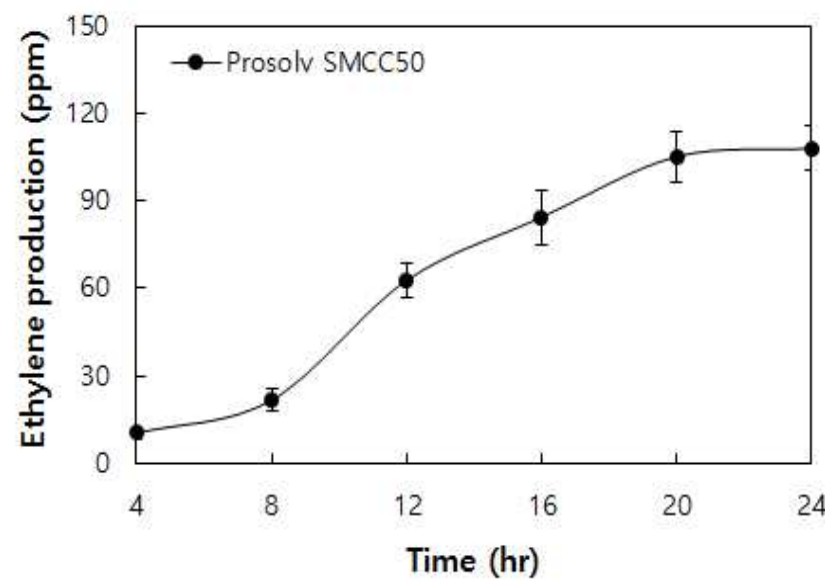

Fig. 5. Changes in ethylene gas evolution of ethylene-producing tablet in $25^{\circ} \mathrm{C}$ sealed jars.

Vertical bars represent the means $\pm S E$ ( $n=5$ ). 
이상의 결과를 종합하면 에틸렌 발생 타블렛 제조에 적 합한 부형제는 Prosolv SMCC 50 부형제 이며, 본 연구에서 개발된 타블렛을 통해서 청과물 도·소매점에서 판매시기를 조절하면서 원예산물을 후숙시켜 판매가 가능해진다면 관 행적인 유통과정에서 발생된 일시적인 후숙으로 인한 손실 을 줄일 수 있을 것으로 기대된다.

\section{요 약}

본 연구는 에테폰과 부형제를 혼합하여 에틸렌 발생 타 블렛을 제조하였고, 에틸렌 가스 활성조건을 구명한 결과 는 다음과 같다. 온도조건별 타블렛의 에틸렌 발생량은 온 도가 높을수록 많은 발생을 보였다. Activator $\mathrm{pH}$ 조건별 에틸렌 발생량은 $\mathrm{pH} 7.0$ 및 9.0 조건에서는 발생량이 약 $2 \mathrm{ppm}$ 으로 미미하였으나, $\mathrm{pH} 13.0$ 에서 타블렛의 에틸렌 발생량은 Prosolv 부형제 $94.05 \mathrm{ppm}, \mathrm{HPMC}$ 부형제 126.28 $\mathrm{ppm}$, Crosscamellose 부형제 $100.11 \mathrm{ppm}$ 으로 각각 나타났 다. 제조된 타블렛의 마손도는 Prosolv 부형제 $0.1 \%, \mathrm{HPMC}$ 부형제 $0.3 \%$, Crosscamellose 부형제 $54.1 \%$ 로 나타나 Crosscamellose 타블렛은 부적합하다고 판단되었다. 붕해 도의 경우 각각의 부형제에 따라 큰 차이를 보였으며, Prosolv 부형제 1분, HPMC 부형제 7분 이상, Crosscamellose 부형제 5분으로 각각 나타났다. 최종 선정된 부형제인 Prosolv 타블렛의 시간대별 에틸렌 발생 측정결과 가스포집 20시간 까지 에틸렌 발생량은 꾸준히 증가하였지만 20시 이후의 발생은 미미하였고 지속적인 가스 발생은 처리 후 20시간으로 나타났다.

\section{감사의 글}

이 논문은 한국연구재단에서 지원하는 2013년도 일반연 구자 지원 사업 [과제명: 친환경적인 에틸렌 가스 발생 Tablet과 activator 개발 및 실용화 기술 연구]의 일환으로 수행되었기에 이에 감사드립니다.

\section{References}

1. Zhang L, Li S, Liu X, Song C, Liu X (2012) Effects of ethephon on physicochemical and quality properties of kiwifruit during ripening. Postharvest Biol Technol, $65,69-75$

2. Park SJ, Chung DS, Hong SS, Kim YB (1998) Application of a simple ethylene generating kit for removal of astringency and softening of persimmon (Diospyros kaki Thunb.). J Korean Soc Hort Sci, 39, 727-731

3. Hong SR, Yang YJ, Park YM (2009) Effect of postharvest ethylene treatment on the quality characteristics in processed berry product of 'Campbell Early' grape. Korean J Hort Sci Technol, 27, 426-431

4. Edgerton LJ, Blanpied GD (1968) Regulation of growth and fruit maturation with 2-chloroethanephosphonic acid. Nature, 219, 1064-1065

5. Worku Z, Herner RC, Carolus RL (1975) Effect of stage of ripening and ethephon treatment on color content of paprika pepper. Sci Hort, 3, 239-245

6. Lougheed EC, Franklin EW (1972) Effects of temperature on ethylene evolution from ethephon. Can J Plant Sci, 52, 769-773

7. Warner HL, Leopold AC (1969) Ethylene evolution from 2-chloroethylphosphonic acid. Plant Physiol, 44, 156-158

8. Gamlen MJ, Seager H, Warrack JK (1982) The structure and tablet properties of paracetamol granules prepared in a fluidized bed and by wet massing. Int $\mathrm{J}$ Pharm Technol Prod Manu, 3, 108-114

9. Jun YB, Min BH, Kim SI, Kim YI (1989) Preparation and evaluation of acetaminophen tablets. J Korean Pharm Sci, 19, 123-129 